\title{
Synergistic Neuroprotective Effects of a Natural Product Mixture against AD Hallmarks and Cognitive Decline in Caenorhabditis elegans and an SAMP8 Mice Model
}

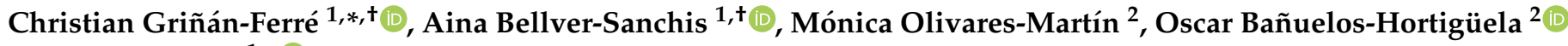 \\ and Mercè Pallàs ${ }^{1, *(\mathbb{D})}$ \\ 1 Pharmacology Section, Department of Pharmacology, Toxicology and Therapeutic Chemistry, Faculty of \\ Pharmacy and Food Sciences, Institute of Neuroscience, University of Barcelona (NeuroUB), Av. Joan XXIII \\ 27-31, 08028 Barcelona, Spain; abellversanchis@gmail.com \\ 2 R\&D Department, Biosearch S.A. Camino de Purchil 66, 18004 Granada, Spain; \\ molivares@biosearchlife.com (M.O.-M.); obanuelos@biosearchlife.com (O.B.-H.) \\ * Correspondence: christian.grinan@ub.edu (C.G.-F.); pallas@ub.edu (M.P.) \\ + These authors contributed equally to this work.
}

Citation: Griñán-Ferré, C.; Bellver-Sanchis, A.; Olivares-Martín, M.; Bañuelos-Hortigüela, O.; Pallàs, M. Synergistic Neuroprotective Effects of a Natural Product Mixture against AD Hallmarks and Cognitive Decline in Caenorhabditis elegans and an SAMP8 Mice Model. Nutrients 2021, 13, 2411. https://doi.org/ $10.3390 /$ nu13072411

Academic Editor:

Panteleimon Giannakopoulos

Received: 24 June 2021

Accepted: 12 July 2021

Published: 14 July 2021

Publisher's Note: MDPI stays neutral with regard to jurisdictional claims in published maps and institutional affiliations.

Copyright: (c) 2021 by the authors. Licensee MDPI, Basel, Switzerland. This article is an open access article distributed under the terms and conditions of the Creative Commons Attribution (CC BY) license (https:// creativecommons.org/licenses/by/ $4.0 /)$.

\begin{abstract}
The study of different natural products can provide a wealth of bioactive compounds, and more interestingly, their combination can exert a new strategy for several neurodegenerative diseases with major public health importance, such as Alzheimer's disease (AD). Here, we investigated the synergistic neuroprotective effects of a mixed extract composed of docosahexaenoic acid, Ginkgo biloba, D-pinitol, and ursolic acid in several transgenic Caenorhabditis elegans (C. elegans) and a senescenceaccelerated prone mice 8 (SAMP8) model. First, we found a significantly higher survival percentage in the C. elegans group treated with the natural product mixture compared to the single extract-treated groups. Likewise, we found a significantly increased lifespan in group of C. elegans treated with the natural product mixture compared to the other groups, suggesting synergistic effects. Remarkably, we determined a significant reduction in $\mathrm{A} \beta$ plaque accumulation in the group of $C$. elegans treated with the natural product mixture compared to the other groups, confirming synergy. Finally, we demonstrated better cognitive performance in the group treated with the natural product mixture in both AD models (neuronal A $\beta$ C. elegans strain CL2355 and the SAMP8 mice model), confirming the molecular results and unraveling the synergist effects of this combination. Therefore, our results proved the potential of this new natural product mixture for AD therapeutic strategies.
\end{abstract}

Keywords: aging; AD hallmarks; Alzheimer's disease; nutritional intervention; natural extracts; C. elegans; SAMP8

\section{Introduction}

Alzheimer's disease (AD) is known as a neurodegenerative disorder with major impacts among the elderly, being the most common form of dementia [1], and is estimated to affect 131 million people by 2050 [2]. The key common pathological hallmarks of AD include the deposition of amyloid- $\beta$ (A $\beta)$ and neurofibrillary tangles (NFTs), leading to a progressive decline in cognitive function and memory loss [3]. Nevertheless, the pathogenesis of AD appears to be complex and multifactorial, in which incidence increases with age, and age is the most important risk factor for the development of the disease. This fact promotes more than one pathological factor [4], such as oxidative stress (OS) [5] and short life expectancy [6], among others.

Extensive studies conducted in vitro and in vivo support a direct link between OS and AD pathology [6-8], involving Aß-induced synaptic dysfunction [5], neuronal death [9], and neurotransmitter deficits [10], highlighting its critical role in cognitive decline [11,12]. OS is caused by the overproduction of reactive oxidative species (ROS), which can damage 
the central nervous system (CNS) through oxygen modification of macromolecules such as lipids, proteins, and nucleic acids [13]. This increase of ROS has been associated with the age-dependent reduction of antioxidant enzymes [14], resulting in altered synaptic activity and neurotransmission in neurons leading to cognitive dysfunction. Accordingly, evidence reports that the accumulation of $\mathrm{A} \beta$ can exacerbate mitochondrial dysfunction and ROS production, contributing to a vicious cycle [15].

Despite extensive pharmacotherapeutic research regarding AD treatments, even with the recent approval of aducanumab [16], none of the approved approaches are entirely successful, leading to new approaches in lifestyle modification and its potential to prevent/delay age-related cognitive decline. In particular, greater emphasis has been placed on implementing non-pharmacological interventions that might prevent $\mathrm{AD}$ or reduce the progression of the disease $[17,18]$. Indeed, the roles of lifestyle interventions and nutraceuticals in preventing many neurodegenerative diseases are highly appreciated in the literature, and are especially relevant for AD [19].

Growing evidence has identified many natural products that can delay the aging process or the onset of age-related disease, including cognitive decline [20]. In this regard, in vivo studies have investigated and adopted several natural products such as Ginkgo biloba (Gb) [21-23], D-pinitol [24], ursolic acid (UA) [25-27], and docosahexaenoic acid (DHA) [28-30], among others, for their beneficial effects against AD through the modulation of different molecular events. Thus, findings from in vitro studies follow the same line, reporting modulations in events critical for AD [31-34]. For instance, numerous studies have described that the beneficial action of $\mathrm{Gb}$ is mainly due to its free radical scavenging action, as it effectively attenuates oxidative damage triggered by $\mathrm{H}_{2} \mathrm{O}_{2} / \mathrm{FeSO}_{4}$ in brain granule cells $[35,36]$. Moreover, extensive clinical trials with the aforementioned dietary compounds are ongoing [37-40], although studies and more extended intervention periods are necessary to define optimal dosages. Thus, despite natural extracts being widely used and evaluated, their efficacy for AD's preventive or curative strategy remains controversial, in that most of these trials do not support robust clinical effects for AD. Interestingly, combinations of different active ingredients in extracts might lead to additive or synergistic effects, giving better disease-modifying activity [41,42]. Studies evaluating the synergistic effects of the above natural compounds for the treatment of $\mathrm{AD}$ are lacking. Hence, the aim of this work follows the hypothesis that the combination of several extracts $[43,44]$ may promote synergistic effects and pave the way to quick and better activity regarding cognitive decline and AD hallmarks with minimal side effects.

For this purpose, we used Caenorhabditis elegans (C. elegans) as an in vitro model organism and the senescence-accelerated mouse prone 8 (SAMP8) model to evaluate the neuroprotective role of a natural product mixture composed of $\mathrm{Gb} 50.4 \mathrm{mg} / \mathrm{L}$, DHA $49.3 \mathrm{mg} / \mathrm{L}$, D-pinitol $20.4 \mathrm{mg} / \mathrm{L}$, and UA $16 \mathrm{mg} / \mathrm{L}$. C. elegans has emerged as a powerful tool to study the underlying mechanisms that give rise to aging-associated neurodegenerative diseases [45]. Thus, it allows us to determine the effects of the mixture in behavioral and molecular improvements as well as modulations in lifespan. We used the transgenic strain CL2006, which expresses human $A \beta_{1-42}$ under control of a muscle-specific promoter and responds to $A \beta_{1-42}$ aggregation with progressive adult-onset paralysis, to evaluate the effects of the selected compounds on $A \beta$ toxicity [46]. Furthermore, to identify a neuronal behavioral phenotype, strain CL2355, in which $A \beta$ is expressed in neurons, and its control, CL2122, were used [47].

Moreover, to evaluate whether the same effect could be observed in mammals, we used the SAMP8 mouse, a mouse model of age-related cognitive decline and late-onset AD (LOAD) [48,49]. SAMP8 is a mice model established through phenotypic selection from a common genetic pool of the AKR/J-strain of mice [50]. Besides, this strain displays behavioral abnormalities and cognitive decline [51]. Thus, features such as oxidative damage associated with mitochondrial dysfunction [52] that cause the overproduction of amyloid precursor protein (APP) processing [53] and pathological accumulations of hyperphosphorylated tau [54], which are implicated in age-dependent cognitive decline [55], 
made SAMP8 a suitable mouse model to evaluate the effects of the natural product mixture treatment for $\mathrm{AD}$.

\section{Materials and Methods}

\subsection{Study Design}

The overall objective of the study was to evaluate the synergistic effect of a natural product mixture. The first part of this study was to determine the beneficial effect of the product mixture on aging hallmarks in C. elegans through cognitive and molecular techniques. The second aim of the study was to validate resultant beneficial effects in a vertebrate model, SAMP8. For all animal experiments, we ensured blinded outcome assessment. The sample size for the intervention was chosen following previous studies in our laboratory and using one of the available interactive tools (http:/ /www.biomath.info/ power/index.html). According to each assay, we used $n=120-150$ or 50-70 as total for at least three replicates in $C$. elegans. For mice, we used $n=36$ for cognitive tests SAMR1 $(n=12)$, SAMP8 $(n=24)$, see Figure 1.
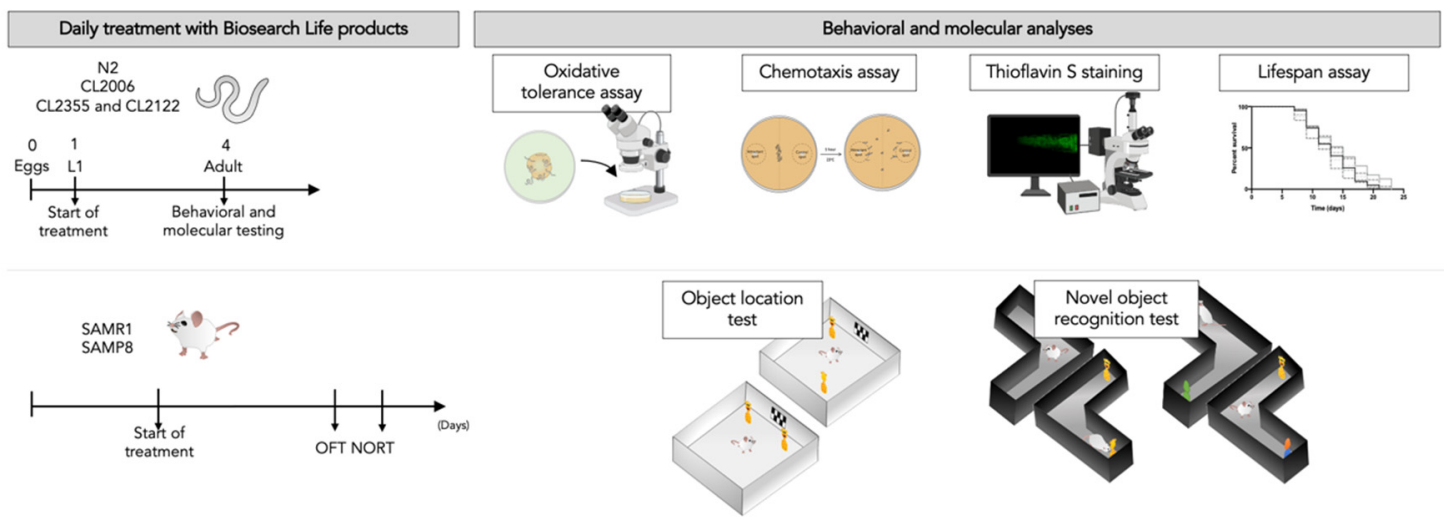

Figure 1. Representative experimental design with schematic behavioral and molecular studies. L: larval stage; SAMR1: Senescence-Accelerated Mouse Resistant 1; SAMP8: Senescence-accelerated mouse prone 8; OFT: Open field test; NORT: Novel object recognition test.

\subsection{Worm Strains, Maintenance, and General Methods}

Strains used in this work and abbreviations are listed in Table 1. All the strains were backcrossed to Bristol strain N2 (WT) five to twelve times. Standard methods were used for culturing and observing C. elegans, unless otherwise noted. Wild-type nematodes were propagated at $20^{\circ} \mathrm{C}$, while transgenic strains were maintained at $16^{\circ} \mathrm{C}$ in a temperaturecontrolled incubator on solid nematode growth medium (NGM) seeded with Escherichia coli (E. coli) OP50 strain as a food source. To obtain the age synchronized population of eggs, gravid adults were treated with an alkaline hypochlorite solution $(0.5 \mathrm{M} \mathrm{NaOH}, \sim 2.6 \%$ $\mathrm{NaClO}$ ) for 5-7 min. Fertilized eggs were suspended in S-medium for $12 \mathrm{~h}$ and L1 larvae were allowed to hatch overnight in the absence of food.

Table 1. List of C. elegans strains used in this work.

\begin{tabular}{ccc}
\hline Strain & Genotype & Source \\
\hline N2 (Bristol) & C. elegans wild-type & \\
CL2006 & dvIs2 (pCL12 (unc-54/human Abeta peptide 1-42 minigene) + & CGC \\
CL2355 & dvIs50 (pCL45 (snb-1::Abeta 1-42::3' UTR(long) + mtl-2::GFP) I & CGC \\
CL2122 & dvIs15 ((pPD30.38) unc-54(vector $)+($ pCL26) mtl-2::GFP) & CGC \\
\hline
\end{tabular}




\subsection{Mice and Maintenance}

Seven-month-old SAMP8 $(n=24)$ and SAMR1 $(n=12)$ mice were used to perform the behavioral experiments. The animals were divided randomly into three groups: SAMR1 control $(n=12)$, SAMP8 control $(n=12)$, and SAMP8 treated with the natural product mixture extract (SAMP8 Mix) $(n=12)$. The animals had free access to food and water under standard temperature conditions $\left(22 \pm 2{ }^{\circ} \mathrm{C}\right)$ and $12 \mathrm{~h}: 12 \mathrm{~h}$ light-dark cycles (300 lux / 0 lux) All studies were performed in accordance with the Institutional Guidelines for the Care and Use of Laboratory Animals established by the Ethical Committee for Animal Experimentation at the University of Barcelona.

\subsection{Compound Preparation and Treatments}

All vegetal extracts and natural products were provided by Biosearch life (Granada, Spain), and were used without further purification. The proportion of each extract in the natural product mixture was as follows: 38\% Gb, 36\% DHA, 15\% D-pinitol, and 11\% UA.

For C. elegans, extracts were serially diluted in a range between $10 \mathrm{~g} / \mathrm{L}$ and $1.6 \mathrm{~g} / \mathrm{L}$ in 100\% dimethyl sulfoxide (DMSO, Sigma Aldrich, St. Louis, MO, USA). Each concentration was then diluted in MilliQ purified water to obtain a final concentration ranging between $100 \mathrm{mg} / \mathrm{L}$ and $16 \mathrm{mg} / \mathrm{L}$ in $1 \%$ DMSO in well. The natural product mixture was composed of $50.4 \mathrm{mg} / \mathrm{L} \mathrm{Gb}, 49.3 \mathrm{mg} / \mathrm{L}$ DHA, $20.4 \mathrm{mg} / \mathrm{L}$ D-pinitol, and $16 \mathrm{mg} / \mathrm{L}$ ursolic acid-rich extract (Ursolia ${ }^{\circledR}$, Biosearch life, Granada, Spain), maintaining the previously established proportions. In most cases, treatments were performed in liquid culture for 4 days at $20^{\circ} \mathrm{C}$. Each well contained a final volume of $60 \mu \mathrm{L}$, comprising 25-30 animals in the L1 stage, products under study at the appropriate doses, and OP50 inactivated by freeze-thaw cycles and suspended in S-medium complete to a final optical density $=595\left(\mathrm{OD}_{595}\right)$ of $0.9-0.8$ measured in the microplate reader (Benchmark ${ }^{\mathrm{TM}}$ Plus Microplate Reader, BioRad, Hercules, CA, USA). For the chemotaxis assay, synchronized CL2355 and its control CL2122 were treated with products on fresh NGM plates seeded with inactivated E. coli, starting from the L1 stage. They were cultured at $16^{\circ} \mathrm{C}$ for $36 \mathrm{~h}$, and then at $23^{\circ} \mathrm{C}$ for another $36 \mathrm{~h}$.

For mice, the natural product mixture was dissolved in 1.8\% 2-hydroxypropyl- $\beta$ cyclodextrin and administered through drinking water for 4 weeks. Water consumption was controlled each week.

\subsection{C. elegans: Oxidative Tolerance Assay}

Treated, adult, wild-type worms (N2) were transferred onto plates that included $6.2 \mathrm{mM}$ t-butyl hydroperoxide (CAS\# 75-91-2, Alfa Aesar, Kandel, Germany) in NGM agar. The worms were incubated on these plates at $20^{\circ} \mathrm{C}$ for $2 \mathrm{~h}$. Then, the worms were transferred to new NGM plates seeded with OP50, and without t-butyl hydroperoxide. The worms were observed $2 \mathrm{~h}, 24 \mathrm{~h}$, and $48 \mathrm{~h}$ after intervention and scored as dead when they did not respond to repeated prodding with a pick. As a positive control, $58 \mu \mathrm{M}$ vitamin $\mathrm{C}$ (L-(+)-Ascorbic acid 99\%, CAS\# 50-81-7, Alfa Aesar, Kandel, Germany) were used.

\subsection{C. elegans: Chemotaxis Assay}

Nematodes were collected after their respective treatments and washed with M9. Briefly, the assay was performed in $100 \mathrm{~mm}$ NGM plates, $10 \mu \mathrm{L}$ of odorant $(0.5 \%$ benzaldehyde in 96\% ethanol) (CAS\# 100-52-7, Sigma Aldrich, St. Louis, MO, USA), along with $1 \mathrm{M}$ of sodium azide (CAS\# 26628-22-8, Sigma Aldrich, St. Louis, MO, USA) added to the "attractant" spot. On the opposite side, $10 \mu \mathrm{L}$ of control odorant (96\% ethanol) along with $1 \mathrm{M}$ of sodium azide were added. Immediately after, 50-60 worms were placed towards the center of the plate. Assay plates were incubated at $23{ }^{\circ} \mathrm{C}$ for $1 \mathrm{~h}$ and were scored according to the chemotaxis index $(\mathrm{CI})$ as follows: $\mathrm{CI}=$ (number of worms at attractant-number of worms at control)/total number of worms. In each experiment, at least 60 worms from each group were analyzed. 


\subsection{C. elegans: Thioflavin-S Staining A $\beta$ Aggregation}

Age-synchronized CL2006 worms were fixed in $4 \%$ paraformaldehyde/PBS, pH 7.5, for $24 \mathrm{~h}$ at $4{ }^{\circ} \mathrm{C}$, and permeabilized in $5 \%$ fresh $\beta$-mercaptoethanol, $1 \%$ Triton $\mathrm{X}-100$, $125 \mathrm{~mm}$ Tris, $\mathrm{pH} 7.5$, at $37^{\circ} \mathrm{C}$ for another $24 \mathrm{~h}$. The nematodes were stained with $0.125 \%$ Thioflavin S (ThS) (CAS\# 1326-12-1, Sigma Aldrich, St Louis, MO, USA) in 50\% ethanol for $2 \mathrm{~min}$, de-stained in $50 \% \mathrm{EtOH}$ for $2 \mathrm{~min}$, washed three times with PBS, and transferred in approximately $10 \mu \mathrm{L}$ volume on a droplet of Fluoromount G (CAT\#17984-25, Electron Microscopy Sciences, Hatfield, PA, USA) on a glass slide for microscopy. Fluorescence images were acquired using a $20 \AA \sim$ objective of a fluorescence microscope. Amyloid deposits in the head regions of the worms were quantified by counting the number of ThS-positive spots using ImageJ, and were expressed as Aß deposits/anterior area.

\subsection{C. elegans: Lifespan Assay}

Worms were treated as described above in liquid culture for four days, starting at the $\mathrm{L} 1$ stage. However, to prevent progeny production, $1 \mu \mathrm{L}$ of $5^{\prime}$-fluorodeoxyuridine (FUdR, CAS\# 50-91-9, Apollo scientific, Stockport, UK), at a final concentration of $120 \mu \mathrm{M}$, was added at day 4 . After treatment, approximately 30 young adult worms were placed on three different NGM plates per condition and transferred to freshly seeded plates every three days, scoring dead animals. An animal was considered dead if no mechanical response was elicited upon three light touches on the head with a platinum wire.

\subsection{SAMP8 Mice: Novel Object Recognition Test}

The novel object recognition test (NORT) protocol employed was a modification of $[51,56]$. Briefly, mice were placed in a $90^{\circ}$, two-arm, 25-cm-long, 20-cm-high, 5-cm-wide black maze. Before performing the test, the mice were individually habituated to the apparatus for $10 \mathrm{~min}$ over three days. On day four, the animals were allowed to explore freely a $10 \mathrm{~min}$ acquisition trial (first trial), during which they were placed in the maze in the presence of two identical, novel objects at the end of each arm. After a delay ( $2 \mathrm{~h}$ and $24 \mathrm{~h}$ ), the animal was allowed to explore two objects one old object and one novel object. The time that mice explored the novel object (TN) and time that mice explored the old object (TO) were measured. A discrimination index (DI) was defined as $(\mathrm{TN}-\mathrm{TO}) /(\mathrm{TN}+\mathrm{TO})$. Exploration of an object was defined as pointing the nose towards at a distance $\leq 2 \mathrm{~cm}$ and/or touching it with the nose. Turning or sitting around the object was not considered exploration. To avoid object preference bias, objects were counterbalanced.

\subsection{SAMP8 Mice: Object Location Test}

The object location test (OLT) is a well-established task based on the spontaneous tendency of rodents to spend more time exploring a novel object location than a familiar object location, and recognizing when an object has been relocated [57,58]. Briefly, the test was performed over three days in a wooden box $(50 \mathrm{~cm} \times 50 \mathrm{~cm} \times 25 \mathrm{~cm})$, in which three walls were white except one that was black. The first day, the box was empty, and the animals just habituated to the open field arena for $10 \mathrm{~m}$ in. The second day, two objects were placed in front of the black wall, equidistant from each other and the wall. The objects were $10 \mathrm{~cm}$ high and identical. The animals were placed into the open field arena and allowed to explore both objects and surroundings for $10 \mathrm{~min}$. Afterward, animals were returned to their home cages, and the OLT apparatus was cleaned with $70 \% \mathrm{EtOH}$. The third day, one object was moved in front of the white wall to test spatial memory. Trials were recorded using a camera mounted above the open field area, and the total exploration time was determined by scoring the amount of time (seconds) spent sniffing the object in the new location (TN) and the object in the old location (TO). To evaluate the cognitive performance, the DI was calculated, which is defined as (TN-TO)/(TN+TO). 


\subsection{Statistics}

All statistical analysis was conducted using GraphPad Prism GraphPad Prism ver. 9 statistical software. Groups were compared with one-way analysis of variance (ANOVA), followed by the Tukey post hoc test. In some cases, comparison between groups was also performed by two-tailed student's t-test for independent replicates. For the further statistical analysis of $C$. elegans survival assay, the Kaplan-Meier survival plot was constructed, which illustrates the percentage of live animals against time. Data are expressed as the mean \pm standard error of the mean (SEM) of at least $n=3$. Statistical significance was considered when $p$ values were $<0.05$. The statistical outliers were determined with Grubs' test and removed from the analysis.

\section{Results}

\subsection{Natural Product Mixture Attenuates Oxidative Stress in C. elegans}

To investigate if the natural products and mixture have any beneficial effects on OS, we tested them after exposure to the chemical oxidant Tert-butyl $(6.2 \mathrm{mM})$. We found that each product group did not reach protection against OS in comparison with the untreated control. Additionally, we obtained a significant reduction in the percent survival in comparison with the vitamin C group (Figure 2). On the other hand, the worms pre-treated with the natural product mixture (dose) were significantly protected against tert-butyl $(6.2 \mathrm{mM})$ induced OS in comparison with the untreated group, and reached the percent of survival worms close to the vitamin $C$ group $(58 \mu \mathrm{M})$, demonstrating the synergistic effect of the combined administration of the products (Figure 2).

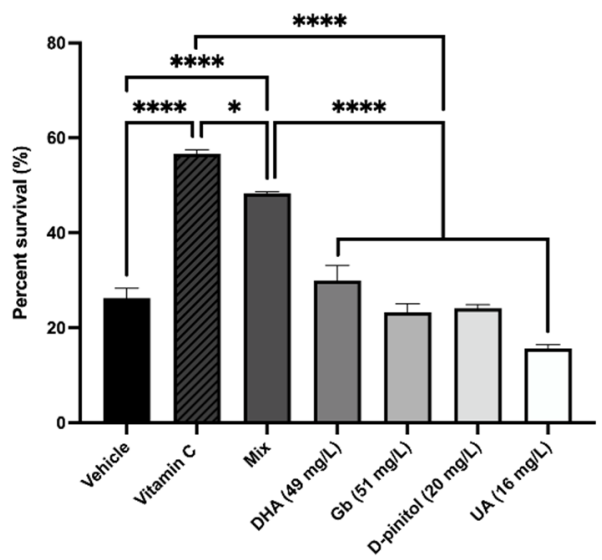

Figure 2. Summary of the OS response in different C. elegans N2 (WT) groups after treatment with each extract treatment, natural product mixture, or vitamin $C(58 \mu \mathrm{M})$. Values represented are mean \pm standard error of the mean (SEM); $n=3$ with $120-150$ worms in each group. ${ }^{*} p<0.05 ;{ }^{* * * *} p<0.0001$. DHA: docosahexaenoic acid; Gb: Ginkgo biloba; UA: ursolic acid.

\subsection{Mean Lifespan Extension by Natural Product Mixture in C. elegans}

Further, we studied the effects by examining changes in lifespan in C. elegans after different natural product treatments and mixtures. Firstly, we did not find any significant change among groups with use of the Kaplan-Meier curve (Figure 3B). However, the mean lifespan was extended by up to $15 \%$ with the natural product mixture treatment in comparison with the DHA, D-pinitol, and UA groups, demonstrating synergistic effect (Figure 3A), whereas there were no changes between the mixture and Gb group due to the well-described effects of $\mathrm{Gb}$ on lifespan. 
A

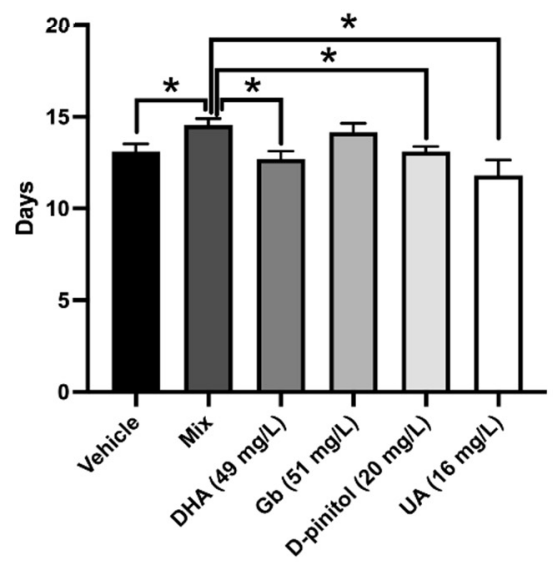

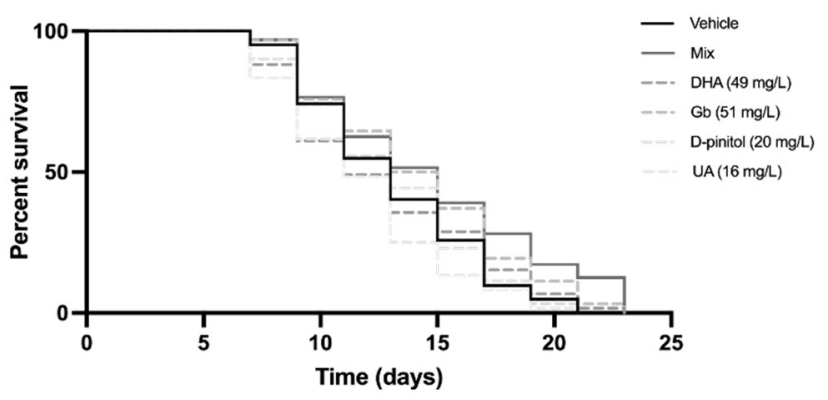

Figure 3. Kaplan-Meier curve for the survival of C. elegans on different extracts (A). The lifespan means of the C. elegans treated and control groups with DMSO 1\% (B). Values represented are mean \pm standard error of the mean (SEM); $n=3$ with 60-70 worms in each group. * $p<0.05$. DHA: docosahexaenoic acid; Gb: Ginkgo biloba; UA: ursolic acid.

3.3. Natural Product Mixture Suppresses Neuronal A $\beta$ Expression-Induced Defectd in Chemotaxis Behavior in Transgenic C. elegans (CL2355)

We used a transgenic strain, CL2355, to investigate whether the inhibitory effects of the natural product mixture on $A \beta$ oligomerization would protect neurons against $A \beta$. The chemotaxis index (CI) was scored for all groups on day 5 and is a measure of the fraction of worms that are able to arrive at the attractant side. Figure 4 shows that the CL2355 strain exhibits a significant reduction in the CI compared to the control strain CL2122. Moreover, each natural product when separated shows a slight tendency to increase the CI compared to the CL2355 strain, but not significantly. Interestingly, a significant increase was observed in the CI in the mixture-treated group compared to the CL2355 group, demonstrating the synergistic effects and restoring chemotaxis behavior to the control strain CL2122 (Figure 4). These results suggest that the natural product mixture might protect neurons against $A \beta$-induced toxicity and rescue neuronal $A \beta$ expression-induced defects in chemotaxis behavior.

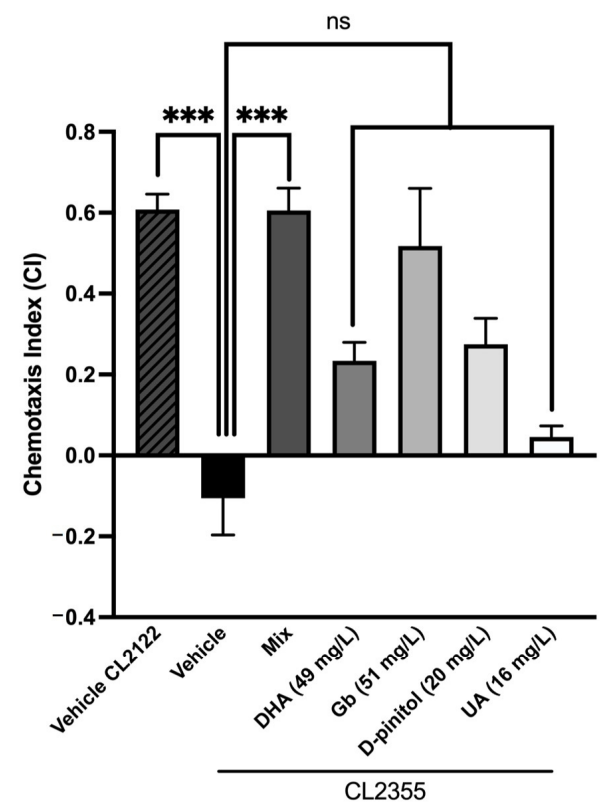

Figure 4. Chemotaxis assay results in the neuronal $A \beta$ strain CL2355. Values represented are mean \pm standard error of the mean (SEM); $n=3$ with $120-150$ worms in each group. ${ }^{* * *} p<0.001$; ns: non-significant. DHA: docosahexaenoic acid; Gb: Ginkgo biloba; UA: ursolic acid. 


\subsection{Natural Product Mixture Improves Amyloid- $\beta$ Burden in Transgenic C. elegans (CL2006)}

Next, we scored the number of AB deposits in the head of the C. elegans strain CL2006 to evaluate whether the inhibitory effects of the mixture versus each individual compound on $A \beta$ oligomerization would reduce the degree of amyloidosis. In addition, Figure $5 B$ respectively shows $A \beta$ deposits (white arrows) detected in CL2006 but not in the wild-type (N2). Figure 5A shows that the mixture group had a remarkable effect on the deposits of the $A B 1-42$ peptide, suggesting that this composition could decrease the aggregation of $A B$ species significantly in a synergistic way. However, the different product groups (DHA, Gb, D-pinitol, and UA) did not have any effect on the deposits of the Aß1-42, demonstrating that the synergistic effect obtained in the mixture group is not apparent (Figure 5A).

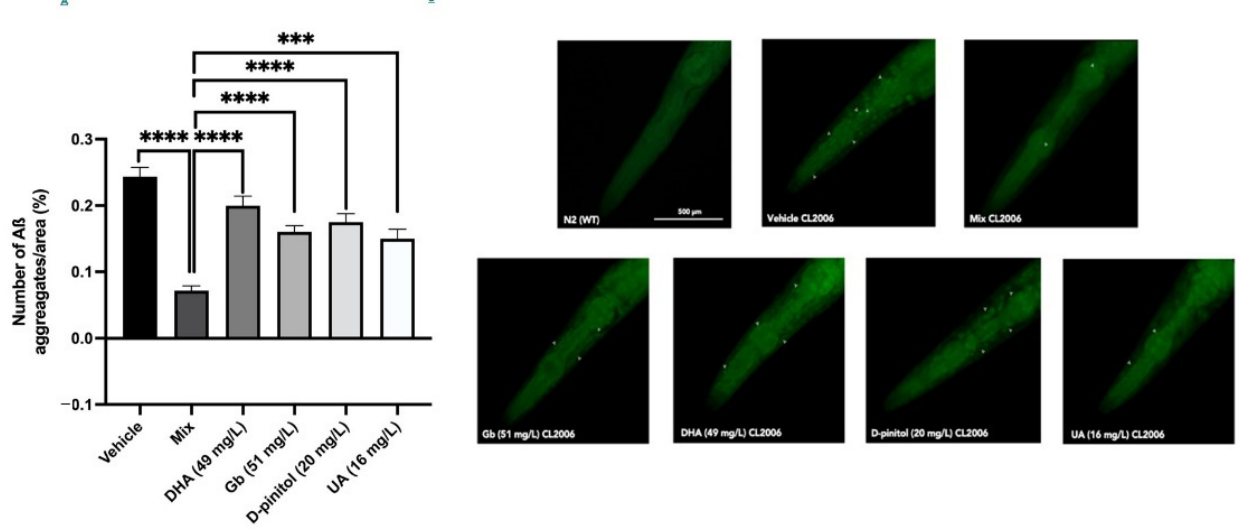

Figure 5. Quantification of ThS-positive particles in the head region of the CL2006 strain (A). Representative images from each group tested $(\mathbf{B})$. Values represented are mean \pm standard error of the mean (SEM); $n=4$ with 50-60 worms in each group. ${ }^{* * *} p<0.0001$. DHA: docosahexaenoic acid; Gb: Ginkgo biloba; UA: ursolic acid.

\subsection{Product Mixture Improves Cognitive Decline Presented by the SAMP8 Mice Model}

We evaluated the beneficial effects on SAMP8 cognition after treatment with the natural product mixture through NORT and OLT. NORT evaluation demonstrates the cognitive improvement of the SAMP8 treatment group through both short- and long-term memory tests in comparison with the SAMP8 control group, reaching DI levels of the SAMR1 control group (Figure 6A,B). Regarding the OLT evaluation, significantly higher DI values were observed in the SAMP8 natural product mixture group compared to the SAMP8 control, recovering DI levels to those of the SAMR1 control group (Figure 6C). Thus, both results showed better cognitive performance in the SAMP8 treated with natural products, suggesting the neuroprotective effects of the natural product mixture. 
A

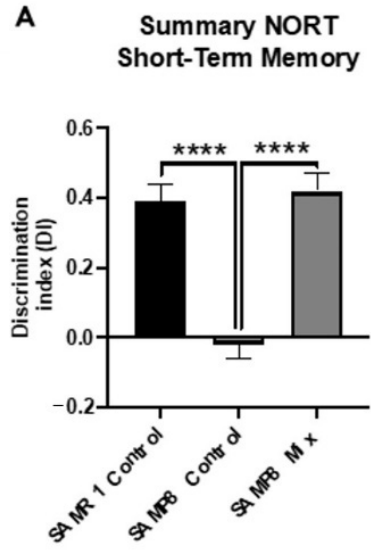

B

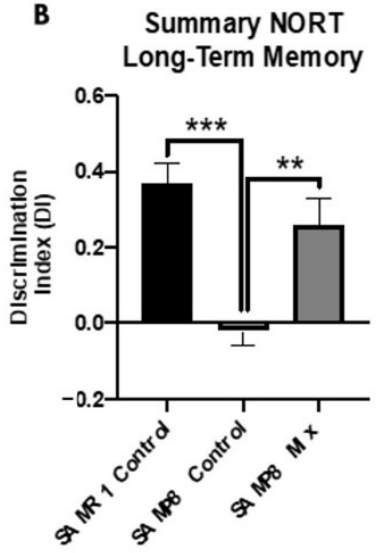

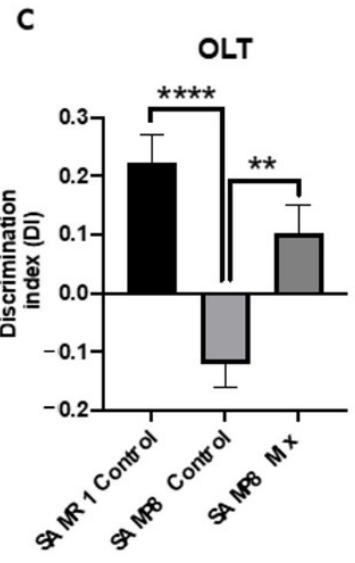

Figure 6. Results of the discrimination index (DI) of short-term memory (A), and long-term memory (B), from novel object recognition tests (NORT) in all Senescence-accelerated mouse prone 8; (SAMP8) groups. Results of the DI from object location test (OLT) (C). Values represented are mean \pm standard error of the mean (SEM); $n=36$ (SAMR1 $\operatorname{control} n=12$; SAMP8 $\operatorname{control} n=12$; SAMP8 natural product mixture $n=12) .{ }^{*} p<0.05 ;{ }^{* *} p<0.01 ;{ }^{* * *} p<0.001 ;{ }^{* * *} p<0.0001$. SAMR1: Senescence-Accelerated Mouse Resistant 1.

\section{Discussion}

Although the controversial aducanumab was recently Food and Drug Administration (FDA) approved for the treatment of $\mathrm{AD} \mathrm{[16],} \mathrm{there} \mathrm{is} \mathrm{still} \mathrm{no} \mathrm{cure} \mathrm{for} \mathrm{age-related} \mathrm{cognitive}$ decline and $\mathrm{AD}[59,60]$. Natural compounds that exert several beneficial properties through different molecular pathways could represent a promising strategy to prevent or cure agerelated cognitive decline and AD risk [61]. Indeed, a wealth of natural extracts that can relieve AD symptoms have been identified according to different targets and mechanisms. Although some of them have entered clinical trials, most are still in the subclinical trial phase, and further evidence is needed to prove the efficacy of these extracts in clinically relevant animal models of $\mathrm{AD}$ [62]. Interestingly, a growing interest in the synergism between/among different natural compounds targeting $\mathrm{A} \beta$ toxicity in $\mathrm{AD}$ opens up a new insight into non-pharmacological AD research [63,64].

Our main goal was to demonstrate that combining different natural products with similar biological effects increases therapeutic efficacy in $\mathrm{AD}$ in comparison to single extract treatments. Such potentiation effects were produced by using a submaximal or minimal concentration of $38 \%$ DHA, $36 \% \mathrm{~Gb}, 15 \%$ Pinitol, and $11 \% \mathrm{UA}$, which, according to the literature, have not shown any protective effect by themselves, obtaining the proposed composition of the mixture. In this study, we evaluated the synergistic neuroprotective effects of the composition against $\mathrm{AD}$ hallmarks and cognitive decline using two approaches: C. elegans and an AD murine model. The intervention ended on the fifth day for C. elegans when they reached the adult stage, and thereby is a chronic treatment. On the other hand, the SAMP8 intervention was finished when the animals reached seven months old, when cognitive impairment and remarkable pathological similarities to AD are presented, such as OS and aberrant amyloid processing pathway, among others [65].

Several causal mechanisms of brain aging-related impairment have been proposed, and one of the relevant events is OS, which is associated with the etiology of age-related cognitive decline and AD [66]. Thus, it has been reported that OS promotes senescence [67,68], and a shortened lifespan in worms $[69,70]$. Accordingly, similar results were also observed in mice [68]. Considering this evidence, we assessed oxidative tolerance assay in the $C$. elegans WT strain and observed the treatment effect on lifespan up to $48 \mathrm{~h}$ after exposure to Tert-butyl. Of interest, we found that the natural product mixture treatment improved the survival percentage significantly compared to the rest of groups treated with single natural compounds, demonstrating the synergistic protective effects of the composition. 
As previously mentioned, OS occurs early in the progression of the neurodegenerative process presented by $\mathrm{AD}$, supporting its role in the disease [71], and interestingly it is linked to the presence of $A \beta$ plaques [72]. Furthermore, the association between the amounts of $\mathrm{A} \beta$ plaques and cognitive decline is highly correlated $[73,74]$. Here, we demonstrated that the natural product mixture exerted a reduction in $\mathrm{A} \beta$ plaques presented by the transgenic C. elegans strain CL2006, whereas the rest of the groups treated with single compounds showed a slight tendency to reduce $A \beta$ plaques. These results demonstrated again that there was no evidence to suggest this result at those doses. For instance, our natural product mixture contained a dose of $51 \mu \mathrm{g} / \mathrm{mL}$ of $\mathrm{Gb}$, whereas Wu et al. [23] showed that the inhibition of $A \beta$ oligomerization and $A \beta$ deposits in worms was reached at the dose of $100 \mu \mathrm{g} / \mathrm{mL}$ of $\mathrm{Gb}$ (EGb 761), strengthening the synergism-enhancing effects of the mixture produced when using a submaximal dose.

Considering that aging is the main risk factor of $\mathrm{AD}$ [23], we evaluated lifespan in $C$. elegans after treatment with the product mixture. Our study found an extended lifespan by up to $15 \%$ compared to the other groups, except in the Gb group, whose beneficial effects on lifespan are well established at $100 \mu \mathrm{g} / \mathrm{mL}$ [75]. Following our results, no lifespan effects were described, for neither D-pinitol nor DHA at these doses [76]. Additionally, it has been reported that UA prolongs the lifespan of $C$. elegans at concentrations of $100 \mu \mathrm{M}$ [77]. Since our product mixture has a final concentration of the active ingredient UA of approximately $16 \mathrm{mg} / \mathrm{L}$ or $5 \mathrm{uM}$, this might be insufficient. Thus, taking together these findings, we again demonstrated the synergistic effects of the mixed natural extracts [77]. Furthermore, these results linked to the OS results were better in the mix of natural extracts for exploring potential anti-aging drugs. OS has been reported to be a significant cause of aging, and antioxidants have been reported to curtail aging [78,79].

Finally, we showed that the sequence of events manifested in the transgenic worms' behavior shares similar mechanisms with the cognitive impairment in rodents. Our study revealed that the SAMP8 mice treated with the product mixture significantly improved their cognition using chemotaxis assay and NORT. On the one hand, the absence of endogenous $A \beta$ production in the worms offers an opportunity to directly asses the role of $A \beta$ involvement in pathological behaviors [80]. Thus, in using the transgenic strain CL2355, which exhibits defects in chemotaxis behavior due to $A \beta$-induced toxicity, we found that the natural product mixture protects against the pathological phenotype presented by this transgenic strain. Notably, the chemotaxis response in C. elegans is mediated by the activation of several sensory neurons and interneurons to stimulate the motor neurons, being biologically relevant to $A \beta$-induced toxicity [81]. On the other hand, we showed that the natural product mixture chronic treatment in the SAMP8 mice model enhanced their cognitive performance. Thus, these findings supported the idea that treatment with the composition attenuated cognitive decline in both models by modulating several pathways associated with AD hallmarks.

To sum up, our study provides new evidence that the natural product mixture can delay neurodegenerative processes through pleiotropic action, reducing $A \beta$ and OS, promoting cognitive improvement, and increasing lifespan. Our study offers new insights for compound interventions with natural products as a therapeutic strategy to prevent or cure age-related cognitive decline and $\mathrm{AD}$.

\section{Patents}

Composition for use in the treatment of cognitive disorders, U.S. Patent and Trademark Office, as national phase entry of International Patent Application No. PCT/EP2021/050270.

Author Contributions: C.G.-F. and A.B.-S. contributed equally; conceptualization and design of the study, C.G.-F. and M.P.; writing — original draft preparation, C.G.-F. and M.P.; writing—review and editing, A.B.-S., M.O.-M.; O.B.-H., and M.P.; All authors have read and agreed to the published version of the manuscript. 
Funding: This research was funded by the Research and Development Project "GERAS: Nature as a Source of Health for Elderly" (IDI-20190733), supported by the Center for Industrial Technological Development (CDTI) and co-financed by the European Regional Development Fund (FEDER) through the Pluriregional Program of Spain 2014-2020.

Institutional Review Board Statement: All experimental procedures involving animals were followed the standard ethical guidelines of European Communities Council Directive 86/609/EEC and by the Institutional Animal Care and by Generalitat de Catalunya (10291, approved 1/28/2018). All efforts were made to minimize the number of mice used and their suffering.

Informed Consent Statement: Not applicable.

Data Availability Statement: Not applicable.

Conflicts of Interest: The authors declare no conflict of interest.

\section{References}

1. Hou, Y.; Dan, X.; Babbar, M.; Wei, Y.; Hasselbalch, S.G.; Croteau, D.L.; Bohr, V.A. Ageing as a risk factor for neurodegenerative disease. Nat. Rev. Neurol. 2019, 15, 565-581. [CrossRef] [PubMed]

2. Alzheimer's Association 2018 Alzheimer's Disease Facts and Figures. Alzheimers Dement. 2018, 14, 367-429. [CrossRef]

3. Serrano-Pozo, A.; Frosch, M.P.; Masliah, E.; Hyman, B.T. Neuropathological alterations in Alzheimer disease. Cold Spring Harb. Perspect. Med. 2011, 1, a006189. [CrossRef]

4. Fan, L.; Mao, C.; Hu, X.; Zhang, S.; Yang, Z.; Hu, Z.; Sun, H.; Fan, Y.; Dong, Y.; Yang, J. New insights into the pathogenesis of Alzheimer's disease. Front. Neurol. 2020, 10, 1312. [CrossRef]

5. Tönnies, E.; Trushina, E. Oxidative stress, synaptic dysfunction, and Alzheimer's disease. J. Alzheimer's Dis. 2017, 57, 1105-1121. [CrossRef]

6. Kamat, P.K.; Kalani, A.; Rai, S.; Swarnkar, S.; Tota, S.; Nath, C.; Tyagi, N. Mechanism of oxidative stress and synapse dysfunction in the pathogenesis of Alzheimer's disease: Understanding the therapeutics strategies. Mol. Neurobiol. 2016, 53, 648-661. [CrossRef]

7. Calkins, M.J.; Manczak, M.; Mao, P.; Shirendeb, U.; Reddy, P.H. Impaired mitochondrial biogenesis, defective axonal transport of mitochondria, abnormal mitochondrial dynamics and synaptic degeneration in a mouse model of Alzheimer's disease. Hum. Mol. Genet. 2011, 20, 4515-4529. [CrossRef]

8. Manczak, M.; Anekonda, T.S.; Henson, E.; Park, B.S.; Quinn, J.; Reddy, P.H. Mitochondria are a direct site of A $\beta$ accumulation in Alzheimer's disease neurons: Implications for free radical generation and oxidative damage in disease progression. Hum. Mol. Genet. 2006, 15, 1437-1449. [CrossRef]

9. Donev, R.; Kolev, M.; Millet, B.; Thome, J. Neuronal death in Alzheimer's disease and therapeutic opportunities. J. Cell. Mol. Med. 2009, 13, 4329-4348. [CrossRef] [PubMed]

10. Lanari, A.; Amenta, F.; Silvestrelli, G.; Tomassoni, D.; Parnetti, L. Neurotransmitter deficits in behavioural and psychological symptoms of Alzheimer's disease. Mech. Ageing Dev. 2006, 127, 158-165. [CrossRef]

11. Hajjar, I.; Hayek, S.S.; Goldstein, F.C.; Martin, G.; Jones, D.P.; Quyyumi, A. Oxidative stress predicts cognitive decline with aging in healthy adults: An observational study. J. Neuroinflammation 2018, 15, 17. [CrossRef]

12. Head, E. Oxidative damage and cognitive dysfunction: Antioxidant treatments to promote healthy brain aging. Neurochem. Res. 2009, 34, 670-678. [CrossRef]

13. Di Domenico, F.; Perluigi, M.; Butterfield, D.A.; Cornelius, C.; Calabrese, V. Oxidative damage in rat brain during aging: Interplay between energy and metabolic key target proteins. Neurochem. Res. 2010, 35, 2184-2192. [CrossRef]

14. Kim, T.; Pae, C.; Yoon, S.; Jang, W.; Lee, N.J.; Kim, J.; Lee, S.; Lee, C.; Paik, I.; Lee, C. Decreased plasma antioxidants in patients with Alzheimer's disease. Int. J. Geriatr. Psychiatry 2006, 21, 344-348. [CrossRef] [PubMed]

15. Trushina, E.; McMurray, C.T. Oxidative stress and mitochondrial dysfunction in neurodegenerative diseases. Neuroscience 2007, 145, 1233-1248. [CrossRef] [PubMed]

16. Mahase, E. FDA Approves Controversial Alzheimer's Drug despite Uncertainty over Effectiveness. BMJ $2021,373,1462$. [CrossRef]

17. McGrattan, A.M.; McGuinness, B.; McKinley, M.C.; Kee, F.; Passmore, P.; Woodside, J.V.; McEvoy, C.T. Diet and inflammation in cognitive ageing and Alzheimer's disease. Curr. Nutr. Rep. 2019, 8, 53-65. [CrossRef] [PubMed]

18. Canevelli, M.; Lucchini, F.; Quarata, F.; Bruno, G.; Cesari, M. Nutrition and dementia: Evidence for preventive approaches? Nutrients 2016, 8, 144. [CrossRef] [PubMed]

19. Schelke, M.W.; Hackett, K.; Chen, J.L.; Shih, C.; Shum, J.; Montgomery, M.E.; Chiang, G.C.; Berkowitz, C.; Seifan, A.; Krikorian, R. Nutritional interventions for Alzheimer's prevention: A clinical precision medicine approach. Ann. N. Y. Acad. Sci. 2016, 1367, 50. [CrossRef]

20. Dominguez, L.J.; Barbagallo, M. Nutritional prevention of cognitive decline and dementia. Acta Bio Med. Atenei Parm. 2018, 89, $276-290$

21. Ge, W.; Ren, C.; Xing, L.; Guan, L.; Zhang, C.; Sun, X.; Wang, G.; Niu, H.; Qun, S. Ginkgo biloba extract improves cognitive function and increases neurogenesis by reducing A $\beta$ pathology in $5 \times$ FAD mice. Am. J. Transl. Res. 2021, $13,1471$. 
22. Qin, Y.; Zhang, Y.; Tomic, I.; Hao, W.; Menger, M.D.; Liu, C.; Fassbender, K.; Liu, Y. Ginkgo biloba extract EGb 761 and its specific components elicit protective protein clearance through the autophagy-lysosomal pathway in tau-transgenic mice and cultured neurons. J. Alzheimer's Dis. 2018, 65, 243-263. [CrossRef]

23. Wu, Y.; Wu, Z.; Butko, P.; Christen, Y.; Lambert, M.P.; Klein, W.L.; Link, C.D.; Luo, Y. Amyloid- $\beta$-induced pathological behaviors are suppressed by Ginkgo biloba extract EGB 761 and ginkgolides in transgenic Caenorhabditis elegans. J. Neurosci. 2006, 26, 13102-13113. [CrossRef]

24. Pitt, J.; Thorner, M.; Brautigan, D.; Larner, J.; Klein, W.L. Protection against the synaptic targeting and toxicity of Alzheimer'sassociated A $\beta$ oligomers by insulin mimetic chiro-inositols. Faseb J. 2013, 27, 199-207. [CrossRef]

25. Habtemariam, S. Antioxidant and anti-inflammatory mechanisms of neuroprotection by ursolic acid: Addressing brain injury, cerebral ischemia, cognition deficit, anxiety, and depression. Oxid. Med. Cell. Longev. 2019, 2019, 8512048. [CrossRef]

26. Ramos-Hryb, A.B.; Pazini, F.L.; Kaster, M.P.; Rodrigues, A.L.S. Therapeutic potential of ursolic acid to manage neurodegenerative and psychiatric diseases. Cns Drugs 2017, 31, 1029-1041. [CrossRef] [PubMed]

27. Liang, W.; Zhao, X.; Feng, J.; Song, F.; Pan, Y. Ursolic acid attenuates beta-amyloid-induced memory impairment in mice. Arq. Neuropsiquiatr. 2016, 74, 482-488. [CrossRef]

28. Patrick, R.P. Role of phosphatidylcholine-DHA in preventing APOE4-associated Alzheimer's disease. Faseb J. 2019, 33, 1554-1564. [CrossRef] [PubMed]

29. Zhou, M.; Ding, L.; Wen, M.; Che, H.; Huang, J.; Zhang, T.; Xue, C.; Mao, X.; Wang, Y. Mechanisms of DHA-enriched phospholipids in improving cognitive deficits in aged SAMP8 mice with high-fat diet. J. Nutr. Biochem. 2018, 59, 64-75. [CrossRef]

30. Quinn, J.F.; Raman, R.; Thomas, R.G.; Yurko-Mauro, K.; Nelson, E.B.; Van Dyck, C.; Galvin, J.E.; Emond, J.; Jack, C.R.; Weiner, M. Docosahexaenoic acid supplementation and cognitive decline in Alzheimer disease: A randomized trial. JAMA 2010, 304, 1903-1911. [CrossRef] [PubMed]

31. Park, Y.H.; Shin, S.J.; Hong, S.B.; Kim, S.; Nam, Y.; Kim, J.-J.; Lim, K.; Kim, J.-S.; Kim, J.; Jeon, S.G. Omega-3 Fatty Acid-Type Docosahexaenoic Acid Protects against A $\beta$-Mediated Mitochondrial Deficits and Pathomechanisms in Alzheimer's DiseaseRelated Animal Model. Int. J. Mol. Sci. 2020, 21, 3879. [CrossRef] [PubMed]

32. Yoon, J.-H.; Youn, K.; Ho, C.-T.; Karwe, M.V.; Jeong, W.-S.; Jun, M. p-Coumaric acid and ursolic acid from corni fructus attenuated $\beta$-Amyloid25-35-induced toxicity through regulation of the NF-кB signaling pathway in PC12 cells. J. Agric. Food Chem. 2014, 62, 4911-4916. [CrossRef]

33. Gohil, K.; Packer, L. Global gene expression analysis identifies cell and tissue specific actions of Ginkgo biloba extract, EGb 761 . Cell. Mol. Biol. (Noisy-Le-Grand) 2002, 48, 625-631.

34. Heo, H.-J.; Cho, H.-Y.; Hong, B.; Kim, H.-K.; Heo, T.-R.; Kim, E.-K.; Kim, S.-K.; Kim, C.-J.; Shin, D.-H. Ursolic acid of Origanum majorana L. reduces Abeta-induced oxidative injury. Mol. Cells 2002, 13, 5-11.

35. Smith, J.V.; Luo, Y. Studies on molecular mechanisms of Ginkgo biloba extract. Appl. Microbiol. Biotechnol. 2004, 64, 465-472.

36. Wei, T.; Ni, Y.; Hou, J.; Chen, C.; Zhao, B.; Xin, W. Hydrogen peroxide-induced oxidative damage and apoptosis in cerebellar granule cells: Protection by Ginkgo biloba extract. Pharm. Res. 2000, 41, 427-433. [CrossRef]

37. Liu, H.; Ye, M.; Guo, H. An updated review of randomized clinical trials testing the improvement of cognitive function of Ginkgo biloba extract in healthy people and Alzheimer's patients. Front. Pharm. 2020, 10, 1688. [CrossRef]

38. Arellanes, I.C.; Choe, N.; Solomon, V.; He, X.; Kavin, B.; Martinez, A.E.; Kono, N.; Buennagel, D.P.; Hazra, N.; Kim, G. Brain delivery of supplemental docosahexaenoic acid (DHA): A randomized placebo-controlled clinical trial. EBioMedicine 2020, 59, 102883. [CrossRef]

39. Ramírez-Rodríguez, A.M.; González-Ortiz, M.; Martínez-Abundis, E.; Acuña Ortega, N. Effect of ursolic acid on metabolic syndrome, insulin sensitivity, and inflammation. J. Med. Food 2017, 20, 882-886. [CrossRef] [PubMed]

40. Grossman, H.; Marzloff, G.; Luo, X.; LeRoith, D.; Sano, M.; Pasinetti, G. NIC5-15 as a treatment for Alzheimer's: Safety, pharmacokinetics and clinical variables. Alzheimer's Dement. 2009, 5, P259. [CrossRef]

41. Skroza, D.; Mekinić, I.G.; Svilović, S.; Šimat, V.; Katalinić, V. Investigation of the potential synergistic effect of resveratrol with other phenolic compounds: A case of binary phenolic mixtures. J. Food Compos. Anal. 2015, 38, 13-18. [CrossRef]

42. Wang, S.; Wang, D.; Liu, Z. Synergistic, additive and antagonistic effects of Potentilla fruticosa combined with EGb761 on antioxidant capacities and the possible mechanism. Ind. Crop. Prod. 2015, 67, 227-238. [CrossRef]

43. Pemovska, T.; Bigenzahn, J.W.; Superti-Furga, G. Recent advances in combinatorial drug screening and synergy scoring. Curr. Opin. Pharm. 2018, 42, 102-110. [CrossRef]

44. Wagner, H. Synergy research: Approaching a new generation of phytopharmaceuticals. Fitoterapia 2011, 82, 34-37. [CrossRef] [PubMed]

45. Olsen, A.; Vantipalli, M.C.; Lithgow, G.J. Using Caenorhabditis elegans as a model for aging and age-related diseases. Ann. N. Y. Acad. Sci. 2006, 1067, 120-128. [CrossRef]

46. Link, C.D. Expression of human beta-amyloid peptide in transgenic Caenorhabditis elegans. Proc. Natl. Acad. Sci. USA 1995, 92, 9368-9372. [CrossRef]

47. Link, C.D. Invertebrate models of Alzheimer's disease. GenesBrain Behav. 2005, 4, 147-156. [CrossRef]

48. Pallàs, M. Senescence-Accelerated Mice P8: A Tool to Study Brain Aging and Alzheimer's Disease in a Mouse Model. Isrn Cell Biol. 2012, 2012, 917167. [CrossRef] 
49. Takeda, T. Senescence-accelerated mouse (SAM) with special references to neurodegeneration models, SAMP8 and SAMP10 mice. Neurochem. Res. 2009, 34, 639-659. [CrossRef]

50. Morley, J.E.; Farr, S.A.; Kumar, V.B.; Armbrecht, H.J. The SAMP8 Mouse: A Model to Develop Therapeutic Interventions for Alzheimers Disease. Curr. Pharm. Des. 2012, 18, 1123-1130. [CrossRef]

51. Griñan-Ferré, C.; Palomera-Ávalos, V.; Puigoriol-Illamola, D.; Camins, A.; Porquet, D.; Plá, V.; Aguado, F.; Pallàs, M. Behaviour and cognitive changes correlated with hippocampal neuroinflammaging and neuronal markers in female SAMP8, a model of accelerated senescence. Exp. Gerontol. 2016, 80, 57-69. [CrossRef]

52. Griñan-Ferré, C.; Pérez-Cáceres, D.; Gutiérrez-Zetina, S.M.; Camins, A.; Palomera-Avalos, V.; Ortuño-Sahagún, D.; Rodrigo, M.T.; Pallàs, M. Environmental enrichment improves behavior, cognition, and brain functional markers in young senescence-accelerated prone mice (SAMP8). Mol. Neurobiol. 2016, 53, 2435-2450. [CrossRef] [PubMed]

53. Morley, J.E.; Kumar, V.B.; Bernardo, A.E.; Farr, S.A.; Uezu, K.; Tumosa, N.; Flood, J.F. $\beta$-Amyloid precursor polypeptide in SAMP8 mice affects learning and memory. Peptides 2000, 21, 1761-1767. [CrossRef]

54. Porquet, D.; Andrés-Benito, P.; Griñán-Ferré, C.; Camins, A.; Ferrer, I.; Canudas, A.M.; Del Valle, J.; Pallàs, M. Amyloid and tau pathology of familial Alzheimer's disease APP/PS1 mouse model in a senescence phenotype background (SAMP8). Age (Omaha) 2015, 37, 12. [CrossRef] [PubMed]

55. Butterfield, D.A.; Poon, H.F. The senescence-accelerated prone mouse (SAMP8): A model of age-related cognitive decline with relevance to alterations of the gene expression and protein abnormalities in Alzheimer's disease. Exp. Gerontol. 2005, 40, 774-783. [CrossRef]

56. Ennaceur, A.; Delacour, J. A new one-trial test for neurobiological studies of memory in rats. 1: Behavioral data. Behav. Brain Res. 1988, 31, 47-59. [CrossRef]

57. Ennaceur, A.; Meliani, K. A new one-trial test for neurobiological studies of memory in rats. III. Spatial vs. non-spatial working memory. Behav. Brain Res. 1992, 51, 83-92. [CrossRef]

58. Companys-Alemany, J.; Turcu, A.L.; Bellver-Sanchis, A.; Loza, M.I.; Brea, J.M.; Canudas, A.M.; Leiva, R.; Vázquez, S.; Pallàs, M.; Griñán-Ferré, C. A novel NMDA receptor antagonist protects against cognitive decline presented by senescent mice. Pharmaceutics 2020, 12, 284. [CrossRef] [PubMed]

59. Cummings, J. New approaches to symptomatic treatments for Alzheimer's disease. Mol. Neurodegener. 2021, 16, 2.

60. Knopman, D.S.; Jones, D.T.; Greicius, M.D. Failure to demonstrate efficacy of aducanumab: An analysis of the EMERGE and ENGAGE trials as reported by Biogen, December 2019. Alzheimer's Dement. 2021, 17, 696-701. [CrossRef]

61. Russo, P.; Frustaci, A.; Del Bufalo, A.; Fini, M.; Cesario, A. Multitarget drugs of plants origin acting on Alzheimer's disease. Curr Med. Chem. 2013, 20, 1686-1693. [CrossRef] [PubMed]

62. Ma, Y.; Yang, M.; Li, X.; Yue, J.; Chen, J.; Yang, M.; Huang, X.; Zhu, L.; Hong, F.; Yang, S. Therapeutic effects of natural drugs on Alzheimer's disease. Front. Pharm. 2019, 10, 1355. [CrossRef]

63. Choi, R.C.Y.; Zhu, J.T.T.; Yung, A.W.Y.; Lee, P.S.C.; Xu, S.L.; Guo, A.J.Y.; Zhu, K.Y.; Dong, T.T.X.; Tsim, K.W.K. Synergistic action of flavonoids, baicalein, and daidzein in estrogenic and neuroprotective effects: A development of potential health products and therapeutic drugs against Alzheimer's disease. Evid. Based Complement. Altern. Med. 2013, 2013, 635694. [CrossRef]

64. Cheung, D.W.-S.; Koon, C.-M.; Wat, E.; Ko, C.-H.; Chan, J.Y.-W.; Yew, D.T.-W.; Leung, P.-C.; Chan, W.-Y.; Bik-San Lau, C.; Fung, K.-P. A herbal formula containing roots of Salvia miltiorrhiza (Danshen) and Pueraria lobata (Gegen) inhibits inflammatory mediators in LPS-stimulated RAW 264.7 macrophages through inhibition of nuclear factor $\mathrm{kB}(\mathrm{NF} \mathrm{B})$ pathway. J. Ethnopharmacol. 2013, 145, 776-783. [CrossRef] [PubMed]

65. Bayram, B.; Nikolai, S.; Huebbe, P.; Ozcelik, B.; Grimm, S.; Grune, T.; Frank, J.; Rimbach, G. Biomarkers of oxidative stress, antioxidant defence and inflammation are altered in the senescence-accelerated mouse prone 8. Age (Omaha) 2013, 35, $1205-1217$. [CrossRef] [PubMed]

66. Youssef, P.; Chami, B.; Lim, J.; Middleton, T.; Sutherland, G.T.; Witting, P.K. Evidence supporting oxidative stress in a moderately affected area of the brain in Alzheimer's disease. Sci. Rep. 2018, 8, 11553. [CrossRef]

67. Honma, T.; Shinohara, N.; Ito, J.; Kijima, R.; Sugawara, S.; Arai, T.; Tsuduki, T.; Ikeda, I. High-fat diet intake accelerates aging, increases expression of Hsd11b1, and promotes lipid accumulation in liver of SAMP10 mouse. Biogerontology 2012, 13, 93-103. [CrossRef]

68. Tsuduki, T.; Honma, T.; Nakagawa, K.; Ikeda, I.; Miyazawa, T. Long-term intake of fish oil increases oxidative stress and decreases lifespan in senescence-accelerated mice. Nutrition 2011, 27, 334-337. [CrossRef]

69. Zhou, K.I.; Pincus, Z.; Slack, F.J. Longevity and stress in Caenorhabditis elegans. Aging (Albany Ny) 2011, 3, 733. [CrossRef]

70. Van Raamsdonk, J.M.; Hekimi, S. Reactive oxygen species and aging in Caenorhabditis elegans: Causal or casual relationship? Antioxid. Redox Signal. 2010, 13, 1911-1953. [CrossRef]

71. Nunomura, A.; Perry, G.; Aliev, G.; Hirai, K.; Takeda, A.; Balraj, E.K.; Jones, P.K.; Ghanbari, H.; Wataya, T.; Shimohama, S. Oxidative damage is the earliest event in Alzheimer disease. J. Neuropathol. Exp. Neurol. 2001, 60, 759-767. [CrossRef]

72. Cheignon, C.; Tomas, M.; Bonnefont-Rousselot, D.; Faller, P.; Hureau, C.; Collin, F. Oxidative stress and the amyloid beta peptide in Alzheimer's disease. Redox Biol. 2018, 14, 450-464. [CrossRef]

73. Mormino, E.C.; Papp, K.V. Amyloid accumulation and cognitive decline in clinically normal older individuals: Implications for aging and early Alzheimer's disease. J. Alzheimer's Dis. 2018, 64, S633-S646. [CrossRef] 
74. Näslund, J.; Haroutunian, V.; Mohs, R.; Davis, K.L.; Davies, P.; Greengard, P.; Buxbaum, J.D. Correlation between elevated levels of amyloid $\beta$-peptide in the brain and cognitive decline. JAMA 2000,283, 1571-1577. [CrossRef]

75. Kampkötter, A.; Pielarski, T.; Rohrig, R.; Timpel, C.; Chovolou, Y.; Wätjen, W.; Kahl, R. The Ginkgo biloba extract EGb761 reduces stress sensitivity, ROS accumulation and expression of catalase and glutathione S-transferase 4 in Caenorhabditis elegans. Pharm. Res. 2007, 55, 139-147. [CrossRef]

76. Sugawara, S.; Honma, T.; Ito, J.; Kijima, R.; Tsuduki, T. Fish oil changes the lifespan of Caenorhabditis elegans via lipid peroxidation. J. Clin. Biochem. Nutr. 2013, 52, 139-145. [CrossRef]

77. Naß, J.; Abdelfatah, S.; Efferth, T. Ursolic acid enhances stress resistance, reduces ROS accumulation and prolongs life span in C. elegans serotonin-deficient mutants. Food Funct. 2021, 12, 2242-2256. [CrossRef] [PubMed]

78. Tan, B.L.; Norhaizan, M.E.; Liew, W.-P.-P.; Sulaiman Rahman, H. Antioxidant and oxidative stress: A mutual interplay in age-related diseases. Front. Pharm. 2018, 9, 1162. [CrossRef] [PubMed]

79. Fusco, D.; Colloca, G.; Monaco, M.R.L.; Cesari, M. Effects of antioxidant supplementation on the aging process. Clin. Interv. Aging 2007, 2, 377. [PubMed]

80. Wu, Y.; Luo, Y.; Transgenic, C. elegans as a model in Alzheimer's research. Curr. Alzheimer Res. 2005, 2, 37-45. [CrossRef]

81. Hobert, O. Behavioral plasticity in C. elegans: Paradigms, circuits, genes. J. Neurobiol. 2003, 54, 203-223. [CrossRef] [PubMed] 